\title{
Health related quality of life in older patients with solid tumors and prognostic factors for decline
}

\author{
Lore Decoster $^{\mathrm{a}, *}$, Chantal Quinten ${ }^{\mathrm{b}}$, Cindy Kenis ${ }^{\mathrm{c}}$, Johan Flamaing ${ }^{\mathrm{d}}$, Philip R. Debruyne ${ }^{\mathrm{e}}$, Inge De Groof ${ }^{\mathrm{f}}$, \\ Christian Focan $^{\mathrm{g}}$, Frank Cornelis ${ }^{\mathrm{h}}$, Vincent Verschaeve ${ }^{\mathrm{i}}$, Christian Bachmann ${ }^{\mathrm{j}}$, Dominique Bron ${ }^{\mathrm{k}}$, Sylvie Luce ${ }^{\mathrm{l}}$, \\ Gwenaëlle Debugne $^{\mathrm{m}}$, Heidi Van, den Bulck ${ }^{\mathrm{n}}$, Jean-Charles Goeminne ${ }^{\mathrm{o}}$, Abdelbari Baitar ${ }^{\mathrm{p}}$, Katrien Geboers ${ }^{\mathrm{q}}$, \\ Benedicte Petit ${ }^{\mathrm{r}}$, Christine Langenaeken ${ }^{\mathrm{s}}$, Ruud Van Rijswijk ${ }^{\mathrm{t}}$, Pol Specenier ${ }^{\mathrm{u}}$, Guy Jerusalem ${ }^{\mathrm{v}}$, \\ Jean-Philippe Praet ${ }^{\mathrm{w}}$, Katherine Vandenborre ${ }^{\mathrm{x}}$, Jean-Pierre Lobelle ${ }^{\mathrm{y}}$, Michelle Lycke ${ }^{\mathrm{e}}$, \\ Koen Milisen ${ }^{\mathrm{z}}$, Hans Wildiers ${ }^{\text {aa }}$
}

a Department of Medical Oncology, Oncologisch Centrum, Universitair Ziekenhuis Brussel, Vrije Universiteit Brussel, Brussels, Belgium

${ }^{\mathrm{b}}$ Laboratory of Experimental Oncology (LEO), Department of Oncology, KU, Leuven, Belgium

c Department of General Medical Oncology and Geriatric Medicine, University Hospitals Leuven, Leuven, Belgium

d Department of Geriatric Medicine, University Hospitals Leuven and Department of Chronic Diseases, Metabolism and Ageing - CHROMETA, KU Leuven, Leuven, Belgium

e Cancer Centre, General Hospital Groeninge, Kortrijk, Belgium \& Positive Ageing Research Institute (PARI), Anglia Ruskin University, Chelmsford, UK

${ }^{\mathrm{f}}$ Department of Geriatric Medicine, Iridium Cancer Network Antwerp, St. Augustinus, Wilrijk, Belgium

${ }^{g}$ Department of Oncology, Clinique Saint-Joseph, CHC-Liège Hospital Group, Liège, Belgium

h Department of Medical Oncology, Cliniques Universitaires Saint-Luc, UCL, Brussels, Belgium

i Department of Medical Oncology, GHDC Grand Hôpital de Charleroi, Charleroi, Belgium

j Department of Geriatric Medicine, AZ Sint-Lucas, Gent, Belgium

k Department of Hematology, ULB Institut Jules Bordet, Brussels, Belgium

'Department Medical Oncology, University Hospital Erasme, Université Libre de Bruxelles (ULB), Brussels, Belgium

m Department of Geriatric Medicine, Centre Hospitalier de Mouscron, Mouscron, Belgium

${ }^{\mathrm{n}}$ Department of Medical Oncology, Imelda Hospital, Bonheiden, Belgium

${ }^{\circ}$ Department of Medical Oncology, CHU-UCL-Namur, Site Sainte-Elisabeth, Namur, Belgium

${ }^{\mathrm{P}}$ Department of Medical Oncology, ZNA Middelheim, Antwerp, Belgium

q Centre for Oncology and Hematology, AZ Turnhout, Turnhout, Belgium

${ }^{\mathrm{r}}$ Department of Medical Oncology, Centre Hospitalier Jolimont, La Louvière, Belgium

s Department Medical Oncology, Iridium Cancer Network Antwerp, AZ Klina, Brasschaat, Belgium

${ }^{\mathrm{t}}$ Department Medical Oncology, ZNA Stuivenberg, Antwerp, Belgium

u Department of Medical Oncology, University Hospital Antwerp, Antwerp, Belgium

${ }^{v}$ Department of Medical Oncology, Centre Hospitalier Universitaire Sart Tilman and Liege University, Liege, Belgium

${ }^{w}$ Department of Geriatric Medicine, CHU St-Pierre, Free Universities Brussels, Brussels, Belgium

${ }^{x}$ Department of Medical Oncology, AZ Vesalius, Tongeren, Belgium

y Consultant in Statistics, Beernem, Belgium

${ }^{z}$ Department of Geriatric Medicine, University Hospitals Leuven, Department of Public Health and Primary Care, Academic Centre for Nursing and Midwifery, KU Leuven, Leuven, Belgium

aa Department of General Medical Oncology, University Hospitals Leuven, Department of Oncology, KU Leuven, Leuven, Belgium

\section{A R T I C L E I N F O}

\section{Article history:}

Received 1 October 2018

Received in revised form 18 January 2019

Accepted 25 March 2019

Available online $\mathrm{xxxx}$

\section{Keywords:}

Older patients

Cancer

Health-related quality of life

Geriatric domains

Prognostic factors

\begin{abstract}
A B S T R A C T
Objectives: This study aims to investigate health-related quality of life (HRQOL) at baseline and at follow-up in older patients with cancer and to determine prognostic factors for HRQOL decline.

Methods: A prospective Belgian multicentre $(n=22)$ study was performed. Patients $\geq 70$ years with a malignant tumor and abnormal G8 ( $\leq 14 / 17)$ screening tool were included. Patients underwent geriatric assessment (GA) and HRQOL evaluation with follow up at three months. Uni- and multivariate regression models were performed to determine factors associated $(p<.05)$ with baseline HRQOL and HRQOL decline at follow-up.

Results: Results reflect data collected from 3673 patients. A multivariate analysis showed that younger patients, and those with poor Eastern Cooperative Oncology Group - Performance Status (ECOG-PS), specific tumor types (gastrointestinal, gynaecological and thorax) and higher stage had lower baseline HRQOL. In addition worse functional status and presence of pain, fatigue, depression and malnutrition were associated with lower baseline HRQOL.
\end{abstract}

\footnotetext{
* Corresponding author at: Department of Medical Oncology, UZ Brussel, Oncologisch Centrum, Laarbeeklaan 101, 1090 Brussels, Belgium.

E-mail address: lore.decoster@uzbrussel.be (L. Decoster).
} 
During treatment ( $n=2972$ ), improvement in HRQOL was observed in 1037 patients (35\%) and a decline in 838 patients (28.2\%). In multivariate analysis, stage and presence of baseline comorbidities, pain, fatigue or malnutrition were associated with HRQOL evolution.

Conclusion: Baseline HRQOL in older patients with cancer and an abnormal G8 depends on tumor and age related parameters. During follow-up, HRQOL improved in one third of patients, indicating that they may benefit from cancer treatment while one quarter demonstrated a HRQOL decline for which prognostic factors were identified.

(c) 2019 Elsevier Ltd. All rights reserved.

\section{Introduction}

Health-related quality of life (HRQOL) is influenced both by the malignant disease and its treatment, and is thus an important parameter for physicians treating patients with cancer [1].

Evaluation of baseline and follow-up HRQOL provides knowledge of the effects of the disease and treatment on the patient's sense of wellbeing and may stimulate physician-patient communication, resulting in a better shared decision making [2-5]. In addition, baseline HRQOL may be prognostic for chemotherapy response and for survival [6-8].

HRQOL is an even more important endpoint for older patients with cancer $[9,10]$. Older patients with cancer often give preference to maintenance or improvement of HRQOL rather than an increase in survival $[11,12]$. As a consequence, older patients are less willing to accept severe toxicity and reduced HRQOL. In non-fit older patients with cancer this may complicate treatment decisions even more because HRQOL decreases with increased frailty [13].

Knowledge of baseline HRQOL and its evolution (i.e. improvement, maintenance, deterioration) during treatment as well as of factors influencing HRQOL is therefore essential for treatment decisions in (non-fit) older patients with cancer and may guide appropriate interventions and care. In addition, baseline HRQOL may be a possible stratification factor in studies specific to older patients with cancer in order to reduce imbalance between treatment arms.

For these reasons, the present study aims to investigate baseline and follow-up HRQOL in older patients with solid tumors and to identify prognostic clinical and geriatric characteristics for HRQOL decline.

\section{Patients and Methods}

\subsection{Patient Population}

A prospective, multicenter, observational cohort study with the main goal to investigate the adherence to geriatric recommendations based on a geriatric assessment (GA), was performed in 22 hospitals (eight academic, fourteen non-academic) in Belgium from November 2012 until February 2015 [14]. Patients 70 years and older with a solid tumor (including breast cancer, central nervous system tumors, carcinoma of unknown primary, digestive system tumors, gynaecologic tumors, head and neck tumors, musculoskeletal tumors, skin tumors, thorax tumors, and genitourinary tumors) or hematologic malignancy were included at the time a treatment decision (surgery, systemic therapy, radiotherapy, hormonal therapy, other therapy or a combination) had to be made. The study was approved by the ethical committee of all participating centers (B322201215495).

Here we present a substudy focusing on HRQOL at baseline and during follow-up in this large cohort. For this analysis, patients with hematologic tumors and ophthalmologic tumors were excluded as well as patients who were lost to follow up or deceased after three months.

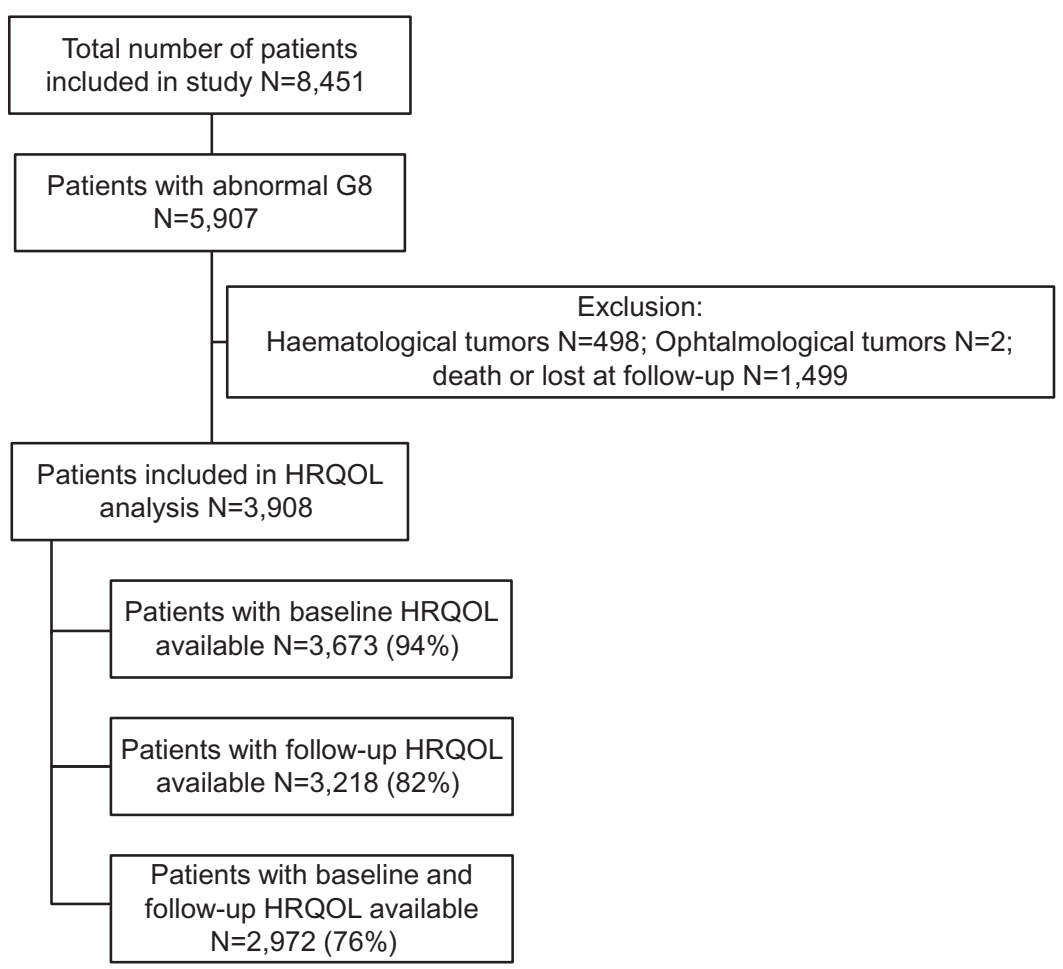

Fig. 1. Patient Flow Chart. Legend: $N=$ Number of patients; HRQOL $=$ Health Related Quality of Life. 


\subsection{Baseline Assessment}

At baseline, all patients were screened using the G8 screening tool $[15,16]$.
In the present analysis only patients with an abnormal G8 screening (score $\leq 14 / 17$ ) were included, since patients with a normal G8 were not referred for baseline GA or HRQOL assessment.

Table 1

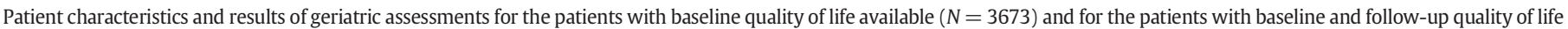
available $(N=2972)$

\begin{tabular}{|c|c|c|c|}
\hline & & $\begin{array}{l}\text { Patients with baseline QoL available } \\
\mathrm{N}=3673\end{array}$ & $\begin{array}{l}\text { Patients with baseline and follow-up QoL available } \\
\mathrm{N}=2972\end{array}$ \\
\hline Patient characteristics & Categories & $\mathrm{N}(\%)$ & $\mathrm{N}(\%)$ \\
\hline \multirow[t]{2}{*}{ Age } & Median & 80 & 79 \\
\hline & Standard deviation & 5.84 & 5.76 \\
\hline \multirow[t]{2}{*}{ Gender } & Female & $2099(57.2)$ & $1681(56.6)$ \\
\hline & Male & $1574(42.9)$ & $1291(43.4)$ \\
\hline \multirow[t]{6}{*}{ Living situation } & Home with partner & $1799(49)$ & $1515(51)$ \\
\hline & Home with family member & $241(6.6)$ & $196(6.6)$ \\
\hline & Home alone & $1345(36.6)$ & $1056(35.5)$ \\
\hline & Assisted Living Community apartment & $85(2.3)$ & $65(2.2)$ \\
\hline & Institution (e.g. nursing home) & $163(4.4)$ & $107(3.6)$ \\
\hline & Other & $40(1.1)$ & $33(1.1)$ \\
\hline \multirow[t]{11}{*}{ Tumor } & Digestive system & $1286(35)$ & $1063(35.8)$ \\
\hline & Breast & $804(21.9)$ & $661(22.2)$ \\
\hline & Genitourinary system & $351(9.6)$ & $281(9.5)$ \\
\hline & Thorax & $353(9.6)$ & $289(9.7)$ \\
\hline & Gynaecologic & $302(8.2)$ & $236(7.9)$ \\
\hline & Head and Neck & $167(4.6)$ & $128(4.3)$ \\
\hline & Skin & $74(2)$ & $57(1.9)$ \\
\hline & CNS & $33(0.9)$ & $25(0.8)$ \\
\hline & Musculoskeletal & $31(0.8)$ & $22(0.7)$ \\
\hline & CUP & $28(0.8)$ & $20(0.7)$ \\
\hline & Prostate & $244(6.6)$ & $190(6.4)$ \\
\hline \multirow[t]{2}{*}{ Time of inclusion } & New diagnosis & $2945(80.2)$ & $2385(80.3)$ \\
\hline & Progression/relapse & $728(19.8)$ & $587(19.8)$ \\
\hline \multirow[t]{5}{*}{ Stage } & Stage I & $479(13)$ & $390(13.1)$ \\
\hline & Stage II & $778(21.2)$ & $645(21.7)$ \\
\hline & Stage III & $900(34.5)$ & $729(24.5)$ \\
\hline & Stage IV & $1223(33.3)$ & $993(33.4)$ \\
\hline & Missing & $293(9)$ & $215(7.2)$ \\
\hline \multirow[t]{2}{*}{ ECOG-PS } & $0-1$ & $2126(57.9)$ & $1803(60.7)$ \\
\hline & $\geq 2$ & $1547(42.1)$ & $1169(39.3)$ \\
\hline \multirow[t]{2}{*}{ Chemotherapy } & No & 2977 (81.05) & $2384(80.22)$ \\
\hline & Yes & $696(18.95)$ & $588(19,78)$ \\
\hline Age-related parameters & Operationalization & $\mathrm{N}(\%)$ & $\mathrm{N}(\%)$ \\
\hline Functional status: & Independent: score $=6$ & $1625(44.2)$ & $1388(46.7)$ \\
\hline $\mathrm{ADL}(6-24)$ & Dependent: score $\geq 7$ & $2048(55.8)$ & $1584(53.3)$ \\
\hline Functional status: & Independent: score 5 (male) or 8 (female) & $1290(35.1)$ & $1095(36.8)$ \\
\hline \multirow[t]{2}{*}{ IADL ( $0-5$ male $/ 0-8$ female) } & Dependent: score $<5$ or 8 & $2371(64.6)$ & $1868(62.9)$ \\
\hline & Missing & $12(0.3)$ & $9(0.3)$ \\
\hline \multirow{3}{*}{ Falls } & No falls & $2366(64.4)$ & $1965(66.1)$ \\
\hline & Presence of falls $(\geq 1)$ & $1301(35.4)$ & $1003(33.8$ \\
\hline & Missing & $6(0.2)$ & $4(0.1)$ \\
\hline \multirow[t]{3}{*}{ Pain (VAS 0-10) } & No pain $(0 / 10)$ & $1812(49.3)$ & $1455(49)$ \\
\hline & Presence of pain $(\geq 1 / 10)$ & $1850(50.4)$ & $1003(50.8)$ \\
\hline & Missing & $11(0.3)$ & $4(0.1)$ \\
\hline \multirow{3}{*}{ Fatigue (VAS 0-10) } & No fatigue $(0 / 10)$ & $940(25.6)$ & $774(26)$ \\
\hline & Presence of fatigue $(\geq 1 / 10)$ & $2701(73.5)$ & $2177(73.3)$ \\
\hline & Missing & $32(0.9)$ & $8(0.3)$ \\
\hline Cognition: & Normal cognition: score $\geq 24$ & $2735(74.5)$ & $2288(77)$ \\
\hline \multirow{2}{*}{ MMSE $(0-30)$} & Cognitive impairment: score $<24$ & $654(17.8)$ & $471(15.9)$ \\
\hline & Missing & $284(7.7)$ & $213(7.2)$ \\
\hline Depression: & Not at risk for depression: score $<5$ & $2319(63.1)$ & $1921(64.6)$ \\
\hline \multirow{2}{*}{ GDS $(0-15)$} & At risk for depression: score $\geq 5$ & 1207 (32.9) & $950(32)$ \\
\hline & Missing & $147(4)$ & $101(3.4)$ \\
\hline Nutrition: & Normal nutritional status: score $\geq 12$ & $769(20.9)$ & $650(21.9)$ \\
\hline \multirow{2}{*}{ MNA-SF (0-14) } & Risk for malnutrition $<12$ & $2907(79.2)$ & $2322(79.1)$ \\
\hline & Missing & $3(0.1)$ & $0(0)$ \\
\hline Comorbidity: & No comorbidity: score 0 & $1007(27.4)$ & $825(27.8)$ \\
\hline $\mathrm{CCI}(0-37)$ & Presence of comorbidity: score $\geq 1$ & 2640 (71.9) & $2134(71.8)$ \\
\hline & Missing & $26(0.7)$ & $13(0.4)$ \\
\hline Polypharmacy & Number 0-4 & $1413(38.5)$ & $1141(38.4)$ \\
\hline & Number $\geq 5$ & $2210(60.2)$ & $1796(60.4)$ \\
\hline & Missing & $50(1.4)$ & $35(1.2)$ \\
\hline
\end{tabular}

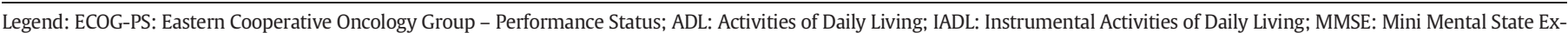
amination; GDS: Geriatric Depression Scale; MNA-SF: Mini Nutritional Assessment- Screening Form; CCI: Charlson Comorbidity Index; 


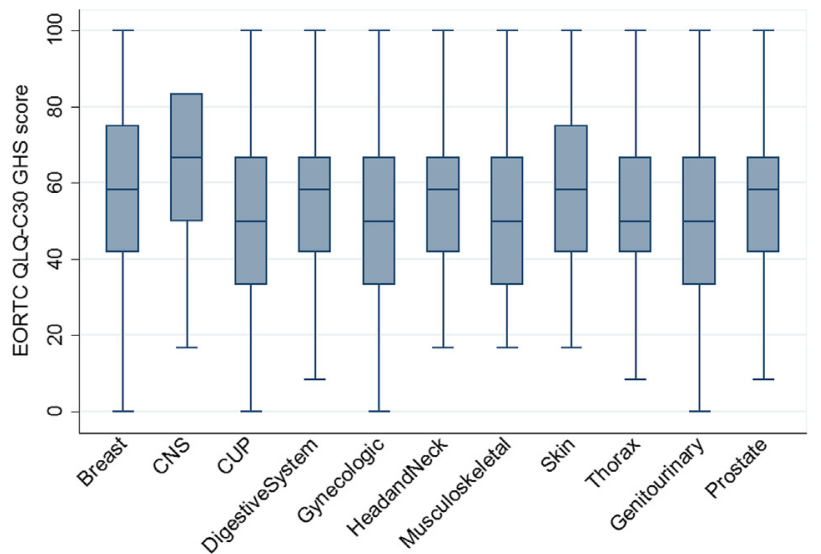

Fig. 2. Boxplots showing the baseline median, interquartile range (25-75 percentiles) and minimum and maximum of the EORTC QLQ-C30 GHS score by tumor type. Legend: EORTC QLQ-C30 GHS = Eoropean Organization of Research and Treatment of Cancer Quality of Life Questionnaire-C30 Global Health Score; CNS = Central Nervous System; CUP: Carcinoma of Unknown Primary.

All included patients underwent a baseline GA, as previously described [14,17]. This GA included following geriatric domains: functional status by activities of daily living (ADL) [18] (independent score 6 versus dependent score $\geq 7$ ) and instrumental activities of daily living (iADL) [19] (independent score $5 / 5$ in males and $8 / 8$ in females versus dependent score $<5$ in males and $<8$ in females), the presence of falls in the past year (no falls versus at least one fall), the presence of pain and fatigue using a visual analogue score (VAS) (no pains versus presence of pain $V A S \geq 1 / 10$ and nog fatigue versus presence of fatigue VAS $\geq 1 / 10$ ), cognition by mini mental state examination (MMSE) [20] (normal cognition score $\geq 24 / 30$ versus cognitive decline score $<24 / 30$ ), mental status using the geriatric depression scale (GDS-15) [21] (no risk for depression score $<5 / 15$ versus risk for depression score $\geq 5 / 15$ ), nutritional status using the mini nutritional assessment short form (MNA-SF) [22-24] (no risk for malnutrition score $\geq 12 / 14$ versus risk for malnutrition score $<12 / 14)$, comorbidities using the Charlson Comorbidity index [25] (no comorbidities versus comorbidities score $\geq 1 / 37$ ) and polypharmacy by the number of drugs taken the week before inclusion (number of drugs $<5$ versus $\geq 5$ ) [26].

In addition a HRQOL evaluation was performed using the European Organization for Research and Treatment Quality of Life Questionnaire core 30 (EORTC QLQ-C30) Global Health Status Scale (GHS). For the present study, the two general questions 29 and 30 were selected: "How would you rate your overall health during the past week?" and "How would you rate your overall quality of life during the past week?". Patients answer these two questions by means of seven-point Likert scales and the two scores are combined to define the GHS. The GHS score is linearly transformed to a $0-100$ score to facilitate statistical interpretation. A higher HRQOL is reported by a higher GHS score. The GHS scale is one of the most frequently used QLQ-C30 subscales and administration of this instrument has been used as the primary endpoint in various trials $[27,28]$.

Classical patient characteristics such as age and gender as well as oncologic parameters such as Eastern Cooperative Oncology Group - Performance Status (ECOG-PS), tumor characteristics (type and stage), and treatment details (surgery / systemic therapy/ radiotherapy / hormonal therapy / other therapy/ combination) were recorded.

\section{Follow-Up Evaluation}

Three months (+/ - two weeks) after the baseline assessment, HRQOL was reassessed using the same questions.

\subsection{Statistical Analysis}

Unadjusted median scores and interquartiles (25th and 75th percentiles) of the baseline HRQOL score were plotted by tumor group.

To assess statistically the association between baseline HRQOL score and different patient, tumor and geriatric characteristics, uni- and multivariate normal regression models were applied. The final multivariate model was achieved in two steps. First, at univariate level, the association between baseline HRQOL and patient, tumor and geriatric characteristics was assessed for each patient. With regards to treatment, patients receiving chemotherapy alone were compared to patients not receiving chemotherapy treatment or receiving a combination of treatments. Those variables statistically significantly at univariate level ( $p \leq .05)$ were included in the final multivariate model. Results were reported with the least mean square difference $(ß)$, its 95\% confidence interval $(\mathrm{CI})$ and the $p$-value. A HRQOL difference of ten points or more between different subgroups was considered clinical significant [27].

HRQOL change was defined as the difference between follow-up and baseline HRQOL score and categorized in three groups; HRQOL decline $(<-10)$, HRQOL improvement $(>10)$ and no HRQOL change over time $(\geq-10$ and $\leq 10)$. Osoba et al. defined a threshold of ten points to categorize patients as clinically improved or deteriorated on any of the EORTC HRQOL scales [29]. A dummy variable was created to categorize patients that reported a HRQOL decline versus those patients that did not report a HRQOL decline; i.e. improvement and no change.

To assess statistically the association between HRQOL decline versus no HRQOL decline (improvement and no change) and patient, tumor and geriatric characteristics, uni- and multivariate logistic regression models were applied. The final multivariate model was achieved in two steps. First, at univariate model, HRQOL decline versus no decline was assessed for each patient characteristic separately. Those variables statistically significant at univariate level $(p \leq .05)$ were included in the final multivariate model. Results were reported with the odds ratio (OR), its 95\% confidence interval (CI) and the $p$-value. OR determine whether a particular exposure is a risk factor for an outcome (i.e. QOL decline or not) [30]. If an OR $=1$ then exposure does not affect odds of outcome; OR $>1$ then exposure associated with higher odds of outcome; $\mathrm{OR}<1$ then exposure associated with lower odds of outcome. The level of significance was set at $p=.05$.

For the regression modeling, missing patient values were imputed using chained equations (MICE) [31]. This method is based on fully conditional specification (FCS) where each incomplete variable is imputed by a separate model. All analysis were performed with Stata.

\section{Results}

\subsection{Patient and Tumor Characteristics}

The patient flow is presented in Fig. 1

Of the 8451 patients included in this study, 5907 had an abnormal G8 ( $\leq 14 / 17)$. For the present HRQOL analysis we excluded patients with a hematologic malignancy $(n=498)$, patients with ophthalmologic tumors $(n=2)$ and patients who were deceased or lost to follow-up after three months ( $n=1499)$.

Of the remaining 3908 patients baseline HRQOL was available for 3673 patients (94\%) and both baseline and follow-up HRQOL were available for 2972 (76\%).

Patient characteristics and GA results are presented in Table 1

\subsection{Baseline $H R Q O L$}

At baseline, the highest median HRQOL was observed in malignant tumors of the skin. The skin tumors $(n=57)$ were stage IV in approximately $33 \%(n=19)$ and consisted of 36 melanoma (63\%), 20 basal cell carcinoma (35\%) and one Merkel cell carcinoma (2\%). The lowest in 
tumors of the thorax, the musculoskeletal system, the genitourinary system, the gynaecological system and carcinomas of unknown primary (CUP). Median HRQOL and interquartile range (25-75 percentiles) as well as minimum and maximum by tumor type are presented in Fig. 2 .

Table 2 presents the results of a uni- and multivariate analysis assessing the statistical significant correlation between baseline HRQOL and patient, tumor and geriatric characteristics.

In the univariate analysis, statistical significant associations $(p<$ .05 ) were observed between baseline HRQOL and different baseline patient and tumor characteristics such as age, ECOG-PS, tumor type, time of inclusion (new diagnosis versus progression/relapse), stage and planned chemotherapy treatment, Moreover, all geriatric characteristics except comorbidity were significantly associated with baseline HRQOL.

In the multivariate analysis assessing the baseline correlation, increasing age was associated with a higher HRQOL $(p<.001)$. Patients with a bad ECOG-PS $(\geq 2)$ had a significantly worse HRQOL compared to patients with a good ECOG-PS ( 0 or 1$)(p<.001)$. Patients with gastrointestinal tumors, gynaecological tumors and tumors of the thorax had significantly lower HRQOL compared to older patients with breast cancer ( $p$-values $0.030 ; 0.017$ and 0.017 respectively). In addition patients with higher stage had worse baseline HRQOL when compared to patients with stage I ( $p=.004,0.042$ and 0.004 for stage II, III and IV respectively). Finally a significantly lower HRQOL was observed in

Table 2

Uni- and multivariate analysis to investigate the association between patient characteristics and geriatric domains and baseline quality of life.

\begin{tabular}{|c|c|c|c|c|c|c|c|c|}
\hline \multirow[t]{2}{*}{ Variables } & \multirow[t]{2}{*}{ Categories } & \multirow{2}{*}{$\begin{array}{l}\text { Number of patients } \\
\mathrm{N}(\%)\end{array}$} & \multicolumn{3}{|c|}{ Univariate analysis } & \multicolumn{3}{|c|}{ Multivariate analysis } \\
\hline & & & $\beta$ & $\mathrm{CI}$ & p-value & $\beta$ & $\mathrm{CI}$ & p-value \\
\hline \multicolumn{9}{|c|}{ Patient and tumor characteristics } \\
\hline Age & & $2972(100)$ & 0.34 & $0.22 ; 0.46$ & $<0.001$ & 0.31 & $0.18 ; 0.44$ & $<0.001$ \\
\hline \multirow[t]{2}{*}{ Gender } & Female & $1681(56.6)$ & & & & & & \\
\hline & Male & $1291(43.4)$ & 0.29 & $-0.17 ; 0.76$ & 0.696 & & & \\
\hline \multirow[t]{6}{*}{ Living Situation } & Home with partner & $1516(51.0)$ & & & & & & \\
\hline & Home with family member & $196(6.6)$ & -0.57 & $-3.53 ; 2.39$ & 0.705 & & & \\
\hline & Home alone & $1055(35.5)$ & -0.50 & $-2.06 ; 1.06$ & 0.529 & & & \\
\hline & Service flat & $65(2.2)$ & 1.82 & $-2.89 ; 6.65$ & 0.456 & & & \\
\hline & Institution & $108(3.7)$ & 1.86 & $-5.37 ; 1.63$ & 0.295 & & & \\
\hline & Other & $32(1.1)$ & 1.88 & $-5.09 ; 8.86$ & 0.596 & & & \\
\hline \multirow[t]{2}{*}{ ECOG-PS } & $0-1$ & $1803(60.7)$ & & & & & & \\
\hline & $\geq 2$ & $1169(39.3)$ & -5.39 & $-6.01 ;-4.79$ & $<0.001$ & -4.49 & $-5.29 ;-3.69$ & $<0.001$ \\
\hline \multirow[t]{11}{*}{ Tumor type } & Breast & $660(22.2)$ & & & & & & \\
\hline & CNS & $24(0.8)$ & 1.13 & $-7.77 ; 10.05$ & 0.802 & 7.80 & $-0.21 ; 15.81$ & 0.056 \\
\hline & CUP & $21(0.7)$ & -8.69 & $-18.61 ; 1.23$ & 0.086 & -7.75 & $-16.62 ; 1.12$ & 0.087 \\
\hline & Digestive system & $1064(35.8)$ & -1.91 & $-4.08 ; 0.25$ & 0.083 & -2.64 & $-4.68 ;-0.60$ & 0.011 \\
\hline & Gynaecologic & $235(7.9)$ & -4.32 & $-7.65 ;-1.01$ & 0.011 & -4.31 & $-7.29 ;-1.32$ & 0.005 \\
\hline & Head and neck & $128(4.3)$ & -1.27 & $-5.49 ; 2.94$ & 0.554 & -0.58 & $-4.35 ; 3.19$ & 0.764 \\
\hline & Musculoskeletal & $24(0.8)$ & -8.23 & $-17.71 ; 1.24$ & 0.089 & -5.61 & $-14.03 ; 2.82$ & 0.192 \\
\hline & Skin & $56(1.9)$ & 1.50 & $-4.53 ; 7.54$ & 0.625 & 0.83 & $-4.53 ; 6.20$ & 0.760 \\
\hline & Thorax & $288(9.7)$ & -4.48 & $-7.56 ;-1.39$ & 0.004 & -4.03 & $-6.89 ;-1.15$ & 0.006 \\
\hline & Genitourinary & $282(9.5)$ & -2.25 & $-5.36 ; 0.86$ & 0.156 & -2.05 & $-4.82 ; 0.73$ & 0.149 \\
\hline & Prostate & $190(6.4)$ & -2.15 & $-5.75 ; 1.44$ & 0.241 & -1.66 & $-4.99 ; 1.66$ & 0.327 \\
\hline \multirow[t]{2}{*}{ Time of inclusion } & New diagnosis & $2385(80.3)$ & & & & & & \\
\hline & Progression/relapse & 587 (19.7) & -3.37 & $-5.17 ;-1.59$ & $<0.001$ & 0.51 & $-1.54 ; 2.58$ & 0.625 \\
\hline \multirow[t]{4}{*}{ Stage } & Stage I & $422(14.2)$ & & & & & & \\
\hline & Stage II & $692(23.3)$ & -3.43 & $-5.94 ;-0.92$ & 0.007 & -3.11 & $-5.60 ;-0.63$ & 0.014 \\
\hline & Stage III & $786(26.5)$ & -3.12 & $-5.51 ;-0.71$ & 0.011 & -1.55 & $-4.02 ; 0.91$ & 0.217 \\
\hline & Stage IV & $1072(36.1)$ & -7.22 & $-9.54 ;-4.09$ & $<0.001$ & -3.32 & $-5.89 ;-0.76$ & 0.001 \\
\hline \multirow[t]{2}{*}{ Chemotherapy } & No & $2384(80.2)$ & & & & & & \\
\hline & Yes & $588(19.2)$ & -3.99 & $-5.82 ;-2.16$ & $<0.001$ & -1.38 & $-3.44 ; 0.66$ & 0.185 \\
\hline \multicolumn{9}{|l|}{ Age related parameters } \\
\hline \multirow[t]{2}{*}{ Funtional status: ADL } & Independent & $1388(46.7)$ & & & & & & \\
\hline & Dependent & $1584(53.3)$ & -6.38 & $-7.80 ;-4.95$ & $<0.001$ & 0.23 & $-1.43 ; 1.94$ & 0.782 \\
\hline Functional status: & Independent & $1094(36.8)$ & & & & & & \\
\hline IADL & Dependent & $1878(63.2)$ & -7.71 & $-9.19 ;-6.23$ & $<0.001$ & -2.20 & $-3.89 ;-0.50$ & 0.011 \\
\hline \multirow[t]{2}{*}{ Falls } & No falls & 1967 (66.2) & & & & & & \\
\hline & Presence of falls & $1005(33.8)$ & -3.74 & $-5.23 ;-2.25$ & $<0.001$ & -0.92 & $-2.48 ; 0.65$ & 0.249 \\
\hline \multirow[t]{2}{*}{ Pain: VAS } & No pain & $1459(49.1)$ & & & & & & \\
\hline & Presence of pain & $1513(50.9)$ & -9.56 & $-10.96 ;-8.16$ & $<0.001$ & -5.35 & $-6.84 ;-3.85$ & $<0.001$ \\
\hline \multirow[t]{2}{*}{ Fatigue: VAS } & No fatigue & $782(26.3)$ & & & & & & \\
\hline & Presence of fatigue & $2190(73.7)$ & -12.76 & $-14.35 ;-11.17$ & $<0.001$ & -7.54 & $-9.24 ;-5.84$ & $<0.001$ \\
\hline Cognition: MMSE & Normal cognition & 1988 (66.9) & & & & & & \\
\hline & Cognitive decline & $984(33.1)$ & -2.86 & $-4.71 ;-1.03$ & 0.002 & 1.04 & $-1.01 ; 3.08$ & 0.321 \\
\hline Depression: GDS & Not at risk for depression & $1988(66.9)$ & & & & & & \\
\hline & At risk for depression & $984(33.1)$ & -13.16 & $-14.63 ;-11.70$ & $<0.001$ & -8.04 & $-9.66 ;-6.41$ & $<0.001$ \\
\hline Nutrition: MNA-SF & Normal nutritional status & $651(21.9)$ & & & & & & \\
\hline & Risk for malnutrition & $2321(78.1)$ & -10.19 & $-11.92 ;-8.46$ & $<0.001$ & -4.93 & $-6.73 ; 0.69$ & $<0.001$ \\
\hline Comorbidity: CCI & No comorbidity & $829(27.9)$ & & & & & & \\
\hline & Presence of comorbidity & $2143(72.1)$ & 1.09 & $-0.50 ; 2.69$ & 0.177 & & & \\
\hline Polypharmacy & Number 0-4 & $1156(38.9)$ & & & & & & \\
\hline & Number $\geq 5$ & $1816(61.1)$ & -3.63 & $-5.09 ;-2.15$ & $<0.001$ & -0.83 & $-3.44 ; 0.66$ & 0.284 \\
\hline
\end{tabular}

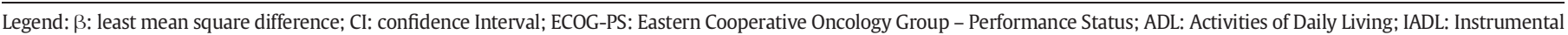

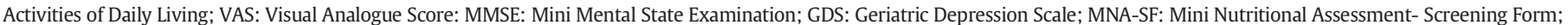
CCl: Charlson Comorbidity Index;

Values in italique indicate statistical significant p-value.

Values in bold italique indicate clinical significant difference in quality of life. 
patients with a dependency on IADL $(p=.006)$, with presence of pain $(\mathrm{p}<.001)$, fatigue $(\mathrm{p}<.001)$ or depression $(<0.001)$ and with malnutrition $(\mathrm{p}<.001)$. However, no clinical significant differences ( $>10$ points) were observed for any of the tumor or age related parameters.

\subsection{HRQOL at Follow-Up}

At follow-up, HRQOL improved with $\geq 10$ points in $1037 / 2972$ patients (35\%) with a mean improvement of 29.75 (CI 28.9; 30.6). HRQOL declined with $\geq 10$ points in $838 / 2972$ patients $(28,2 \%)$ with a mean decline of 29.4 (CI -30.4;-28.4). Patients with tumors of the central nervous system (CNS) experienced most frequently a decline in HRQOL (40\%). A HRQOL improvement was observed most frequently for older patients with musculoskeletal tumors (45.5\%) and carcinoma of unknown primary (45\%). HRQOL change per tumor type is listed in Appendix A.

Table 3 describes the uni- and multivariate analysis to determine which patient, tumor and geriatric characteristics are prognostic for HRQOL decline.

In the multivariate analysis, the odds of experiencing a HRQOL deterioration was higher for those patients who were diagnosed with stage III carcinoma patients (28\%: $p=.025$ ) compared to those patients who were diagnosed with stage I carcinoma at baseline. The odds of experiencing a HRQOL deterioration during treatment was lower for those patients who reported pain $(22 \% ; p=.016)$, fatigue $(38 \%: p=$ $.001)$, malnutrition (22\%: $p=.044)$ at baseline compared to those

Table 3

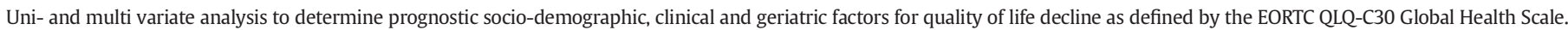

\begin{tabular}{|c|c|c|c|c|c|c|c|c|}
\hline \multirow[t]{2}{*}{ Variables } & \multirow[t]{2}{*}{ Categories } & \multirow{2}{*}{$\frac{\text { Number of patients }}{\mathrm{N}(\%)}$} & \multicolumn{3}{|c|}{ Univariate analysis } & \multicolumn{3}{|c|}{ Multivariate analysis } \\
\hline & & & OR & $\mathrm{CI}$ & $p$-value & OR & $\mathrm{CI}$ & p-value \\
\hline \multicolumn{9}{|l|}{ Patient characteristics } \\
\hline Age & & $2972(100)$ & 1.01 & $0.99 ; 1.02$ & 0.558 & & & \\
\hline \multirow[t]{2}{*}{ Gender } & Female & $1681(56.6)$ & reference & & 0.994 & & & \\
\hline & Male & $1291(43.4)$ & 1.01 & $0.83 ; 1.14$ & & & & \\
\hline \multirow[t]{6}{*}{ Living Situation } & Home with partner & $1516(51.0)$ & reference & & & & & \\
\hline & Home with family member & $196(6.6)$ & 1.04 & $0.69 ; 1.31$ & 0.814 & & & \\
\hline & Home alone & $1055(35.5)$ & 1.04 & $0.85 ; 1.19$ & 0.681 & & & \\
\hline & Service flat & $65(2.2)$ & 1.04 & $0.48 ; 1.43$ & 0.901 & & & \\
\hline & Institution & $108(3.7)$ & 1.18 & $0.81 ; 1.43$ & 0.306 & & & \\
\hline & Other & $32(1.1)$ & 0.46 & $0.26 ; 1.35$ & 0.309 & & & \\
\hline \multirow[t]{2}{*}{ ECOG-PS } & $0-1$ & $1803(60.7)$ & reference & & 0.445 & & & \\
\hline & $\geq 2$ & 1169 (39.3) & 0.94 & $0.26 ; 1.09$ & & & & \\
\hline \multirow[t]{11}{*}{ Tumor type } & Breast & $660(22.2)$ & reference & $0.26 ; 1.37$ & & & & \\
\hline & CNS & $24(0.8)$ & 0.61 & $0.53 ; 4.88$ & 0.229 & & & \\
\hline & CUP & $21(0.7)$ & 1.61 & $0.85 ; 1.32$ & 0.398 & & & \\
\hline & Digestive system & $1064(35.8)$ & 1.06 & $0.84 ; 1.66$ & 0.596 & & & \\
\hline & Gynaecologic & $235(7.9)$ & 1.18 & $0.44 ; 1.26$ & 0.329 & & & \\
\hline & Head and neck & $128(4.3)$ & 0.65 & $0.61 ; 5.43$ & 0.162 & & & \\
\hline & Musculoskeletal & $24(0.8)$ & 1.81 & $0.48 ; 1.56$ & 0.286 & & & \\
\hline & Skin & $56(1.9)$ & 0.87 & $0.73 ; 1.34$ & 0.651 & & & \\
\hline & Thorax & $288(9.7)$ & 0.98 & $0.73 ; 1.34$ & 0.920 & & & \\
\hline & Genitourinary & $282(9.5)$ & 0.99 & $0.89 ; 1.89$ & 0.980 & & & \\
\hline & Prostate & $190(6.4)$ & 1.29 & & 0.170 & & & \\
\hline \multirow[t]{2}{*}{ Time of inclusion } & New diagnosis & $2385(80.3)$ & reference & & & & & \\
\hline & Progression/relapse & $587(19.7)$ & 0.93 & $0.70 ; 1.12$ & 0.462 & & & \\
\hline \multirow[t]{4}{*}{ Stage } & Stage I & $422(14.2)$ & reference & & & reference & & \\
\hline & Stage II & $692(23.3)$ & 1.12 & $0.84 ; 1.33$ & 0.369 & 1.11 & $0.82 ; 1.32$ & 0.453 \\
\hline & Stage III & $786(26.5)$ & 1.29 & $1.07 ; 1.45$ & 0.013 & 1.28 & $1.04 ; 1.45$ & 0.025 \\
\hline & Stage IV & $1072(36.1)$ & 1.18 & $0.94 ; 1.37$ & 0.126 & 1.18 & $0.89 ; 1.38$ & 0.212 \\
\hline \multirow[t]{2}{*}{ Chemotherapy } & No & $2384(80.2)$ & reference & & & & & \\
\hline & Yes & $588(19.2)$ & 0.97 & $0.75 ; 1.15$ & 0.750 & & & \\
\hline \multicolumn{9}{|l|}{ Geriatric domains } \\
\hline \multirow[t]{2}{*}{ Functional status: ADL } & Independent & $1388(46.7)$ & reference & & & & & \\
\hline & Dependent & $1584(53.3)$ & 0.96 & $0.78 ; 1.10$ & 0.608 & & & \\
\hline Functional status: & Independent & $1094(36.8)$ & reference & & & & & \\
\hline \multirow{3}{*}{$\begin{array}{l}\text { IADL } \\
\text { Falls }\end{array}$} & Dependent & $1878(63.2)$ & 0.98 & $0.81 ; 1.14$ & 0.833 & & & \\
\hline & No falls & $1967(66.2)$ & reference & & & & & \\
\hline & Presence of falls & $1005(33.8)$ & 1.16 & $0.99 ; 1.29$ & 0.054 & & & \\
\hline \multirow[t]{2}{*}{ Pain: VAS } & No pain & $1459(49.1)$ & reference & & & reference & & \\
\hline & Presence of pain & $1513(50.9)$ & 0.69 & $0.46 ; 0.88$ & 0.001 & 0.78 & $0.57 ; 0.96$ & 0.016 \\
\hline \multirow[t]{2}{*}{ Fatigue: VAS } & No fatigue & $782(26.3)$ & reference & & & reference & & \\
\hline & Presence of fatigue & $2190(73.7)$ & 0.55 & $0.27 ; 0.78$ & $<0.001$ & 0.62 & $0.35 ; 0.84$ & 0.001 \\
\hline Cognition: MMSE & Normal cognition & $1988(66.9)$ & reference & & & & & \\
\hline & Cognitive decline & $984(33.1)$ & 1.17 & $0.99 ; 1.32$ & 0.062 & & & \\
\hline Depression: GDS & Not at risk for depression & 1988 (66.9) & reference & & & & & \\
\hline & At risk for depression & $984(33.1)$ & 0.84 & $0.63 ; 1.02$ & 0.086 & & & \\
\hline Nutrition: MNA-SF & Normal nutritional status & 651 (21.9) & reference & & & reference & & \\
\hline & Risk for malnutrition & $2321(78.1)$ & 0.78 & $0.54 ; 0.98$ & 0.029 & 0.78 & $0.54 ; 0.99$ & 0.044 \\
\hline Comorbidity: CCI & No comorbidity & 829 (27.9) & reference & & & reference & & \\
\hline & Presence of comorbidity & $2143(72.1)$ & 1.17 & $1.03 ; 1.31$ & 0.024 & 1.17 & $1.01 ; 1.30$ & 0.043 \\
\hline Polypharmacy & Number $0-4$ & $1156(38.9)$ & reference & & & & & \\
\hline & Number $\geq 5$ & $1816(61.1)$ & 0.96 & $0.79 ; 1.12$ & 0.643 & & & \\
\hline
\end{tabular}

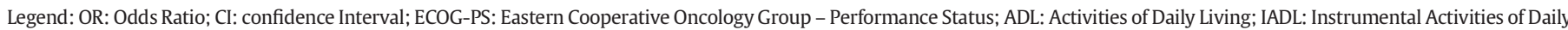

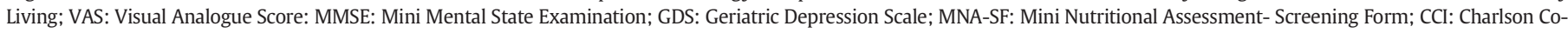
morbidity Index;

Values in italique indicate statistical significant p-value. 
patients who reported no pain, no fatigue or malnutrition at baseline. The odds of experiencing a HRQOL deterioration during treatment was higher for those patients who reported at baseline presence of comorbidity ( $17 \% ; p=.043$ ) compared to those patients who did not experience comorbidities at baseline.

\section{Discussion}

This Belgian prospective study is, to our knowledge, the largest to investigate HRQOL in older patients with solid tumors, who have an abnormal G8 screening tool.

In a multivariate analysis of this study, baseline HRQOL was influenced by patient characteristics such as age and ECOG-PS, tumor characteristics such as type and stage and age related characteristics such as functional status, pain, fatigue, mental status and nutritional status. The findings of our study confirm previous findings in smaller studies where performance status, tumor type, functional status, pain, fatigue and depression were prognostic for baseline HRQOL [32-38]. The association between nutritional status and HRQOL has also been reported in the general older population and in a non small cell lung cancer population $[39,40]$. Interestingly, in our large study.

HRQOL increased with increasing age, which can be explained by some of the oldest patients reporting an extremely good HRQOL. The phenomenon of older patients reporting very good HRQOL has been observed previously in a non-cancer population [41] and could be explained by adaptation which leads to a change of the personal goals and standards [42]. Additionally our study could not confirm the relationship between comorbidity and baseline HRQOL which was reported previously in two smaller studies $[35,36]$. This may be explained by the fact that the Charlson Comorbidity Index is a very objective measure of comorbidity and that subjective assessments of comorbidity by means of self-reported disease burden have been shown to correlate more strongly with HRQOL [43].

At three months follow-up, our study observed a clinical improvement $(>10)$ in HRQOL in one third of older patients with cancer, which was consistent with the observations of Puts et al. at 12 months follow-up [44]. In addition Ronning et al. observed significant improvement in HRQOL at three months after surgery for colorectal cancer, also in the subgroup of frail patients according to GA [45]. We can therefore conclude that a substantial proportion of older patients with cancer demonstrate an improvement in HRQOL during cancer treatment. This is an important observation both for treating physicians and for older patients with cancer when discussing treatment options. Even if the survival benefit is low for certain older patients, an improvement in HRQOL can be considered as a reason to propose a certain treatment modality.

On the other hand, one quarter of older patients with cancer demonstrate a decline in HRQOL during cancer treatment in our study and in the studies of Puts et al. and Esbensen et al. [44,46] In order to identify patients at risk for such a HRQOL decline it is important to identify prognostic factors.

In the study by Puts et al., none of the sociodemographic, health or functional status variables were associated with decline in QOL during the first year after diagnosis [44]. In our study patients experiencing pain, fatigue or malnutrition at baseline demonstrated a significant lower risk of HRQOL decline in multivariate analysis. This is certainly reassuring since these patients have a lower baseline HRQOL. A possible explanation for this observation, may be that treatment of the cancer may have resulted in an improvement or resolution of these complaints. Ebensen et al. identified functional status by means of "contact with district nurse at baseline' and 'need more help in daily living at baseline and mental status by means of 'low level at hope' as prognostic for HRQOL decline at six months [45]. In our larger study, functional status by means of ADL and IADL and mental status by means of GDS- 15 were not prognostic for HRQOL decline at three months.
Finally, our study demonstrated that patient comorbidities at baseline had a higher risk of HRQOL decline than patients with no comorbidities, although there was no significant difference at baseline between these two groups. This observation indicates that patients with comorbidities should be followed with extreme caution during follow-up.

Our study has several limitations. First of all we included only patients with an abnormal G8, which is not a perfect screening tool (sensitivity 65-92\%) to identify unfit patients according to CGA [16]. On the other hand, this may also be considered a strength of our study, since we focus on those patients that are potentially at the highest risk of HRQOL decline. In addition the G8 on itself has shown to be predictive for HRQOL-adjusted survival in older patients with head and neck cancer [47]. Secondly, we excluded patients with hematologic malignancies because they were considered as a different entity. In addition we excluded patients who had died or were lost to follow-up at three months. These may have been some of the frailest patients, but on the other hand a life expectancy of three months is often regarded necessary to consider treatment for cancer. Thirdly, the population in this study is heterogeneous, but this may also be a strength since our results are applicable to a large population of older patients with cancer. Finally the follow-up of three months is relatively short. We therefore do not have information of the evolution of HRQOL at the long term, which may reflect the recuperation of older patients after for example an adjuvant treatment. On the other hand, this short follow-up may also be considered as a strength since it shows that anticancer treatment may very quickly improve HRQOL in a substantial number of patients.

In conclusion, the results of this large Belgian study demonstrate that baseline HRQOL is influenced by different tumor, patient and geriatric characteristics and may therefore be an interesting stratification factor for further studies in older patients with cancer. An important subset of older patients with cancer and an abnormal G8 screening result reported an improvement of HRQOL at follow-up. Since this is an important end point for older patients with cancer, treatment decisions should not be based on age or the presence of an abnormal screening tool. We also identified the presence of comorbidities as a prognostic factor for HRQOL decline at follow-up. Therefore, we encourage integrating conversations about comorbidities in the treatment discussion with these patients.

\section{Author Contribution List}

Conception and design: $\mathrm{LDC}, \mathrm{CQ}, \mathrm{CK}, \mathrm{HW}$

Data collection: all authors

Analysis and interpretation of data: LDC, CQ CK

Manuscript writing: LDC

Approval of final manuscript: all authors

\section{Conflict of Interest Statement}

The authors declare no conflict of interest

\section{Research Support}

This study was funded by the Cancer Plan 2012-2015, a grant provided by the Federal Public Service of Health, Food Chain Safety and Environment, Belgium (KPC_24_A_025). HW is a recipient of a grant of the 'Fonds Voor Wetenschappelijk Onderzoek Vlaanderen' (1802211N).

\section{Appendix A. Supplementary Data}

Supplementary data to this article can be found online at https://doi. org/10.1016/j.jgo.2019.03.018. 


\section{References}

[1] Wedding U, Pientka L, Höffken K. Quality-of-life in elderly patients with cancer: a short review. Eur J Cancer 2007;43:2203-10.

[2] Hilarius DL, Kloeg PH, Gundy CM, Aaronson NK. Use of health-related quality-of-life assessments in daily clinical oncology nursing practive: a community hospital-based intervention study. Cancer 2008;113:628-37.

[3] Velikova G, Booth L, Smith AB, Brown PM, Lynch P, Brown JM, et al. Measuring quality of life in routine oncology practive improves communication and patient wellbeing: a randomized controlled trial. J Clin Oncol 2004;22:714-24.

[4] King S, Exley J, Parks S, Ball S, Bienkowska-Gibbs T, MacLure C, et al. The use and impact of quality of life assessment tools in clinical care settings for cancer patients, with a particular emphasis on brain cancer: insights from a systematic review and stakeholder consultations. Qual Life Res 2016;25:2245-56.

[5] Nicklasson M, Elfström ML, Olofson J, Bergman B. The impact of individual quality of life assessment on psychosocial attention in patients with chest malignanvies: a randomized study. Support Care Cancer 2013;21:87-95.

[6] Lee CK, Stockler MR, Coates AS, Gebski V, Lord SJ, Simes RJ. Self-reported healthrelated quality of life is an independent predictor of chemotherapy treatment benefit and toxicity in women with advanced breast cancer. Br J Cancer 2010;102: 1341-7.

[7] Ediebah DE, Coens C, Zikos E, et al. Does change in health-related quality of life score predict survival? Analysis of EORTC 08975 lung cancer trial. Br J Cancer 2014;110: 2427-33.

[8] Fournier E, Jooste V, Woronoff AS, et al. Health-related quality of life is a prognostic factor for survival in older patients after colorectal cancer diagnosis: a population based study. Dig Liver Dis 2016;48:87-93.

[9] Wildiers Mauer M, Pallis A, et al. End point and trial design in geriatric oncology research: a joint European Organisation for Research and Treatment of Cancer - Alliance for clinical trials in oncology - International Society of Geriatric Oncology position article. J Clin Oncol 2013;31:3711-8.

[10] Scotté F, Bossi P, Carola E, et al. Addressing the quality of life need of older patients with cancer: a SIOG consensus paper and practical guide. Ann Oncol 2018;29: $1718-26$.

[11] Pinquart M, Duberstein PR. Information needs and decision making process in older patients with cancer. Crit Rev Oncol Hematol 2004;51:69-80.

[12] Fried TR, Bradley EH, Towle VR, Allore H. Understanding the treatment preferences of seriously ill patients. N Engl J Med 2002;346:1061-6.

[13] Geesink N, Schoon Y, Van Goor H, Olde-Rikkert M, Melis R. Frailty and quality of life among older people with and without cancer diagnosis: findings from TOPICS-MDS. PLoS One 2017;12:e0189648.

[14] Kenis C, Decoster L, Flamaing J, Debruyne PR, De Groof I, Focan C, et al. Adherence to geriatric assessment-based recommendations in older patients with cancer: a multicenter prospective cohort study in Belgium. Ann Oncol 2018. https://doi.org/10. 1093/annonc/mdy210.

[15] Soubeyran P, Bellera C, Goyard J, Heitz D, Curé H, Rousselot H, et al. Screening for vulnerability in older cancer patients: the ONCODAGE prospective Multicenter cohort study. PLoS One 2014;9:e115060.

[16] Decoster L, Van Puyvelde K, Mohile S, et al. Screening tools for multidimensional health problems warranting a geriatric assessment in older cancer patients: an update on SIOG recommendations. Ann Oncol 2015;2:288-300.

[17] Wildiers H, Heeren P, Puts M, et al. International Society of Geriatric Oncology conensus on geriatric assessment in older patients with cancer. J Clin Oncol 2014; 32:2595-603.

[18] Katz S. Assessing self-maintenance: activities of daily living, mobility, and instrumental activities of daily living. J Am Geriatr Soc 1983;31(12):721-7.

[19] Lawton MP, Brody EM. Assessment of older people: self-maintaining and instrumental activities of daily living. Gerontologist 1969;9(3):179-86.

[20] Folstein MF, Foldestein SE, McHugh PR. "Mini-mental state". A practical method for grading the cognitive state of patients for the clinician. J Psychiatr Res 1975;12(3): 189-983.

[21] Sheikh JI, Yesavage JA. Geriatric Depression Scale (GDS): recent evidence and development of a shorter version. Clin Gerontol 1986;5(1/2):165-73.

[22] Vellas B, Guigoz Y, Garry PJ, Nourhashemi F, Bennahum D, Lauque S, et al. The mini nutritional assessment (MNA) and its use in grading the nutritional state of elderly patients. Nutrition 1999;15(2):116-22.

[23] Lilamand M, Kelaiditi E, Cesari M, Raynaud-Simon A, Ghisolfi A, Guyonnet S, et al. Validation of the mini nutritional assessment-short form in a population of frail elders without disability. Analysis of the Toulouse frailty Patform population in 2013. J Nutr Health Aging 2015;19:570-4.

[24] Lera L, Sanchez H, Angel B, Albala C. Mini nutritional assessment short-form: validation in five Latin American cities. SABE study J Nutr Health Aging 2016;20: 797-805.

[25] Charlson ME, Pompei P, Ales KL, Mackenzie CR. A new method of classifying prog nostic co-morbidity in longitudinal-studies - development and validation. J Chronic Dis 1987;40:373-83.

[26] www.bcfi.be.

[27] Coens C, van der Graaf WTA, Blay JY, Chawla SP, Judson I, Sanfilippo R, et al. Healthrelated quality-of-life results from PALETTE: a randomized, double-blind, phase 3 trial of pazopanib versus placebo in patients with soft tissue sarcoma whose disease has progressed during or after prior chemotherapy-a European Organization for research and treatment of cancer soft tissue and bone sarcoma group global network study (EORTC 62072). Cancer 2015;121(17):2933-41.

[28] Quidde J, Hegewisch Becker S, Graven U, Lerchenmueller C, Killing B, Depenbusch R, et al. Quality of life in patients with metastatic colorectal cancer receiving maintenance therapy after first-line inductive treatment: a quality of life sub-analysis of the AIO KRK 0207 phase III trial. Ann Oncol 2016;27(6). https://doi.org/10.1093/ annonc/mdw370.105.

[29] Osoba D, Rodrigues G, Myles J, Zee B, Pater J. Interpreting the significance of changes in health related quality of life scores. J Clin Oncol 1998;16:139-44.

[30] Szumilas M. Explaining odds ratios. J Can Acad Child Adolesc Psychiatry 2010;19(3): 227-9.

[31] Jolani S, Debray TPA, Koffijberg H, van Buuren S, Moons KGM. Imputation of systematically missing predictors in an individual participant data meta-analysis: a generalized approach using MICE. Stat Med 2015;34(11):1841-63.

[32] Ebensen BA, Osterlind K, Roer O, Hallberg IR. Quality of life of elderly persons with newly diagnosed cancer. Eur J Cancer Care 2004;13:4443-53.

[33] Wedding U, Koch A, Röhrig B, et al. Depression and functional impairment independently contribute to decreased quality of life in cancer patients prior to chemotherapy. Acta Oncol 2008;47:56-62.

[34] Wedding U, Röhrig B, Klippstein A, Brix C, Pientka L, Höffken K. Co-morbidity and functional deficits independently contribute to quality of life before chemotherapy in elderly cancer patients. Support Care Caner 2007;15:1097-104.

[35] Thomé B, Hallberg IR. Quality of life in older people with cancer - a gender perspective. Eur J Cancer Care 2004;13:454-63.

[36] Chang VT, Hwang SS, Feuerman M, et al. Symptom and quality of life survey of medial oncology patients at a veteran at a veteran affairs medical cancer: a note for symptom assessment. Cancer 2000;88:1175-83.

[37] Thomé B, Dykes AK, Hallberg IR, et al. Quality of life in old people with and without cancer. Qual Life Res 2004;13:1067-80.

[38] Vanderwalde NA, Deal AM, Comitz E, et al. Geriatric assessment as a predictor of tolerance, quality of life and outcomes in older patients with head and neck cancers and lung cancers receiving radiation therapy. Int J Radiat Oncol Biol Phys 2017;98: 850-7.

[39] Rasheed S, Woods RT. Malnutrition and quality of life in older people: a systematic review and meta-analysis. Ageing Res Rev 2013;12:561-6.

[40] Polanski J, Jankowska-Polanska B, Uchmanowicz I, et al. Malnutrition and quality of life in patients with non-small-cell lung cncer. Adv Exp Med Biol 2017;1021: $15-26$.

[41] Dello Buono M, Urciuoli O, De Leo D. Quality of life and longevity: a study of centenarians. Age Ageing 1998;27:207-16.

[42] Netuveli G, Blane D. Quality of life in older ages. Br Med Bull 2008;85:113-26.

[43] Bayliss EA, Ellis JL, Steiner JF. Subjective assessments of comorbidity correlate with quality of life health outcomse: initial validation of a comorbidity assessment instrument. Health Qual Life Outcomes 2005;3:51.

[44] Puts MTE, Monette J, Girre V, et al. Quality of life during the course of cancer treatment in older newly diagnosed patients. Results of a prospective pilot study. Ann Oncol 2011;22:916-23.

[45] Ronning B, Wyller TB, Nesbakken A, et al. Quality of life in older and frail patients after surgery for colorectal cancer - a follow-up study. J Geriatr Oncol 2016;7: 195-200.

[46] Esbensen BA, Osterlind K, Hallberg IR. Quality of life of elderly persons with cancer: a 6-months follow-up. Scand J Caring Sci 2007;21:178-90.

[47] Pottel L, Lycke M, Boterberg T, Pottel H, Goethals L, et al. G8 indicates overall and quality-adjusted survival in older head and neck cancer patients treated with curative radiochemotherapy. BMC Cancer 2015;15:875. 